\title{
(a) Synthetic nicotine has arrived
}

\section{OPEN ACCESS}

'Department of Anesthesiology, Duke University School of Medicine, Durham, North Carolina, USA

${ }^{2}$ Department of Psychiatry, Yale School of Medicine, New Haven, Connecticut, USA

\section{Correspondence to}

Dr Sven-Eric Jordt, Department of Anesthesiology, Duke University School of Medicine, Durham, NC 27710-3094, USA; sven.jordt@duke.edu

Received 1 March 2021 Accepted 16 August 2021

Check for updates

(c) Author(s) (or their employer(s)) 2021. Re-use permitted under CC BY-NC. No commercial re-use. See rights and permissions. Published by BMJ.

To cite: Jordt S-E. Tob Control Epub ahead of print: [please include Day Month Year]. doi:10.1136/ tobaccocontrol-2021-056626

Sven-Eric Jordt (i) 1,2

\section{ABSTRACT}

The introduction of a new product line of the popular disposable electronic cigarette brand Puffbar, advertised as containing synthetic nicotine, has drawn attention to the increasing use of synthetic nicotine in marketed products and its uncertain regulatory status. A search of the Truth Tobacco Industry Documents revealed that the industry considered using synthetic nicotine already in the 1960s, efforts that were abandoned due to high costs and insufficient purity. Recent patents revealed renewed efforts to develop more efficient strategies for the synthesis of nicotine. Nicotine exists as two stereoisomers, $S$-nicotine and $R$-nicotine. While $S$-nicotine is the prevalent (>99\%) form of nicotine in tobacco, a market-leading form of synthetic nicotine contains both stereoisomers at equal amounts, raising concerns about inaccurate labelling and the poorly understood health effects of $R$-nicotine. Other manufacturers, including a leading vendor of pharmaceutical grade nicotine, developed stereospecific strategies to synthesise pure $S$-nicotine, now added to electronic cigarette products marketed in the USA and UK. While S-nicotine and $R$-nicotine can be differentiated by enantioselective High Performance Liquid Chromatography (HPLC), differentiation of synthetic (fossil-derived) from tobacco-derived S-nicotine will require development of methods to measure carbon isotope $\left({ }^{14} \mathrm{C}\right.$ or $\left.{ }^{13} \mathrm{C}\right)$ content. Vendors claim that the FDA has no authority to regulate synthetic nicotine as a tobacco product, allowing them to circumvent the premarket tobacco product application process. However, legal analysis suggests that FDA may have the authority to regulate synthetic nicotine as a drug. Alternatively, Congress needs to include nicotine from any source within the legal definition of tobacco products

In US federal regulations, any product containing tobacco-derived materials is deemed a tobacco product. ${ }^{1}$ In addition to the conventional tobacco products, the Food and Drug Administration's (FDA) regulatory authority extends to electronic cigarettes (E-cigarettes) that contain highly purified tobaccoderived nicotine, but no other tobacco-derived constituents. Even the market leading products in the recently introduced tobacco leaf-free nicotine pouch category are considered tobacco products since they contain tobacco-derived nicotine. ${ }^{23}$

The tobacco regulatory science community has occasionally discussed a hypothetical scenario in which a company would market a product containing synthetic nicotine. ${ }^{4}$ Would FDA have regulatory authority over such a product ? Such scenario has ceased to be hypothetical. In February 2021, a countdown clock appeared on the website of Puffbar, announcing a game-changing new product. Puffbar is a popular brand of flavoured disposable E-cigarettes whose market share increased rapidly after FDA prohibited the sale of Juul's candy and berry-flavoured pods. ${ }^{5}$ FDA issued a warning letter to Puffbar on 20
July 2020, ordering the company to stop sales due to lack of premarket authorisation. ${ }^{6}$ However, while the main sales website (puffbar.com) stopped sales, other online vendors, convenience stores and gas stations continued to sell Puffbar-branded disposable E-cigarettes, suggesting that these products were continued to be manufactured or imported illegally, potentially from several sources.

Puffbar revealed the new product as a line of E-cigarettes, stating 'products are created with tobacco-free nicotine. Our nicotine-based products are crafted from a patented manufacturing process, not from tobacco' (figure 1A). ${ }^{7}$ Products are marketed in 3 sizes and with 15 flavours, including a wide range of fruit, berry and candy flavours.

\section{SYNTHETIC NICOTINE: CHEMISTRY AND MANUFACTURERS}

Nicotine is a chiral molecule with two stereoisomers, $S$-nicotine and $R$-nicotine (figure 2A). Tobacco leaf contains $>99 \% S$-nicotine. ${ }^{8}$ A search for the term 'synthetic nicotine' in the Truth Tobacco Industry Documents revealed that the industry considered the use of synthetic nicotine already in the 1960s. A document by British American Tobacco proposed the addition of synthetic nicotine for adjustment of the nicotine/tar ratio in combustible cigarettes. ${ }^{9}$ However, this plan was deemed unacceptable since synthetic nicotine was only available as a racemic mixture, containing both $S$-nicotine and $R$-nicotine at a 50/50 ratio. $S$-nicotine extracted from tobacco was considered safer and more economical. ${ }^{9}$ Analyses by Reynolds in 1967 and Ligget and Myers in 1978 came to the same conclusion. ${ }^{10}{ }^{11}$ Stereoselective synthetic pathways for $S$-nicotine were developed later. ${ }^{12}$ However, while the tobacco industry eagerly pursued the stereoselective synthesis of L-menthol, developed by Nobel Laureate Ryōji Noyori at the flavour manufacturer Takasago (Tokyo, Japan), ${ }^{13}$ the Truth Documents library does not contain any more recent evidence considering the use of synthetic racemic or $S$-nicotine by the major tobacco companies.

Puffbar states that 'Our nicotine-based products are crafted from a patented manufacturing process, not from tobacco', however, the company neither revealed its source of synthetic nicotine in its products nor the chemical process used to manufacture it. $^{7}$ Web searches for tobacco-free nicotine identified additional marketed E-cigarette products containing tobacco-free nicotine. One E-liquid vendor, RXVape, listed a trademarked brand of tobacco-free nicotine (TFN), manufactured by the company, Next Generation Labs (NGL) (figure 1B, table 1). ${ }^{14} 15$ A patent assigned to NGL describes a synthetic pathway starting from ethyl nicotinate, an ester of nicotinic acid (niacin), a synthetic bulk chemical. Ethyl nicotinate is reacted with 


\section{A}

\section{Tobacco Free}

Better Flavor, Better Experience

As a demonstrated pledge to premium quality, Puffs nicotine-based products are created with tobacco-free nicotine. Our nicotine-based products are crafted from a patented manufacturing process, not from tobacco. The result? A virtually tasteless, odorless nicotine without the residual impurities of tobacco-derived nicotine. This dramatically improves flavor while still maintaining the same satisfaction smokers are seeking from their nicotine.

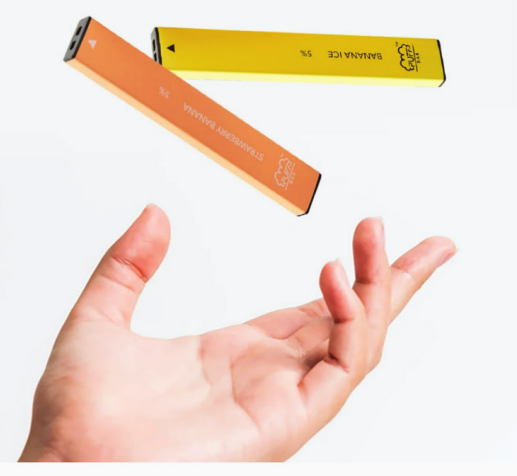

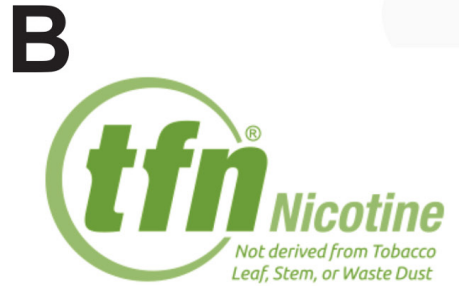

BEWARE OF THE FAKES

\section{What is TFN®}

TFN® Nicotine is not derived from tobacco leaf, stem, reconstituted sheet, expanded or post-production waste dust. The nicotine is made using a patented manufacturing process that begins with a natural starter material, and progressively builds around the molecules of that material to create a pure synthetic nicotine. Almost all E-cig/Vaping brands and e-liquids use tobacco derived nicotine. TFN is devoid of many of the residual impurities that tobacco derived nicotine contain. Most important for adult consumers, TFN is virtually tasteless and odorless, dramatically improving e-juice flavors, while importantly providing the same satisfaction smokers are seeking from their nicotine. With TFN, there is no need to mask the off-flavor and aroma of tobacco-based nicotine. TFN allow manufacturers or crafted vape liquids to make a truly tobacco free vaping product!

\section{TFN@ Nicotine - Putting the Flavor back in Vaping}

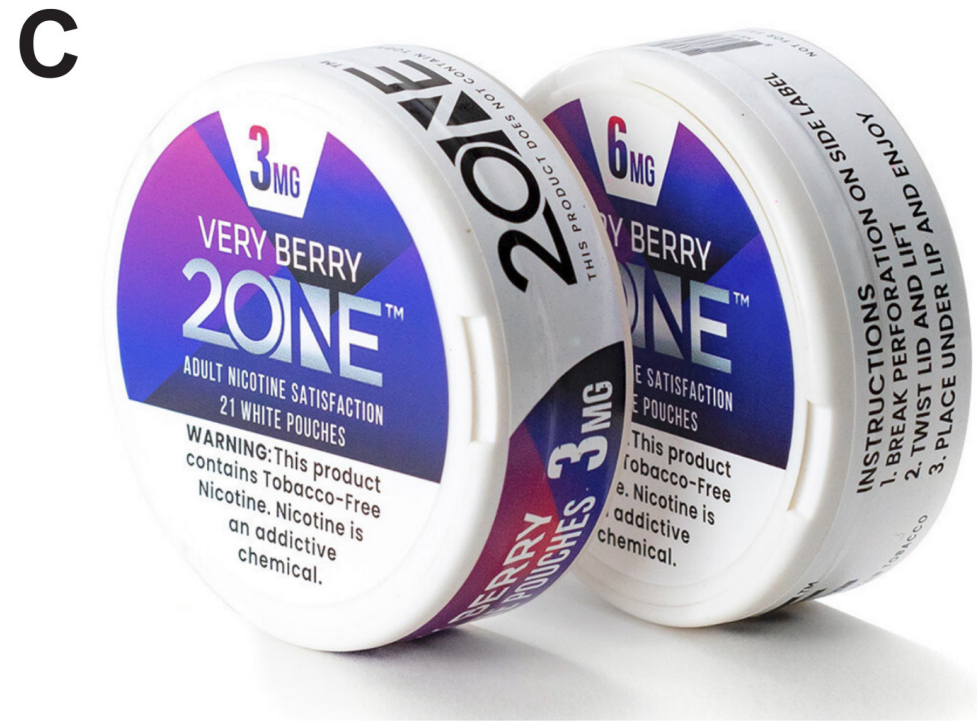

Figure 1 Products containing synthetic nicotine. (A) Puffbar line of electronic cigarettes containing synthetic nicotine, marketed since February 2021. (B) Next Generation Labs' description of synthetic nicotine. (C) 20ne nicotine pouches with warning label stating synthetic nicotine content, available for ordering on Amazon.com.

N-vinyl-2-pyrrolidinone to form myosmine, a tobacco alkaloid. Myosmine is reduced to nornicotine, followed by a methylation step resulting in a racemic $(50 / 50)$ mixture of the nicotine stereoisomers, (S)-nicotine and (R)-nicotine. ${ }^{16}$ NGL's intellectual property was recently recognised by Chinese authorities, enabling the company to enforce its patents in the country where the large majority of E-cigarette products are manufactured. ${ }^{17}$ At least four other US-based E-cigarette vendors were identified selling TFN-branded synthetic nicotine E-liquids. TFN-branded nicotine was also found marketed as an ingredient in at least two brands of nicotine pouch products, NIIN pouches and 20ne pouches, the latter sold on Amazon.com, with a third pouch product line, FRE, stating 'they do contain a non-tobaccoderived nicotine' (figure $1 \mathrm{C}$ ). ${ }^{18-21}$

In contrast to the vendors listed above, two E-liquid web stores, Five Pawns and Tea Time E-Liquids, state that they 
A

TFN<smiles>CN1CCC[C@H]1c1cccnc1</smiles>

S-nicotine $(50 \%)$

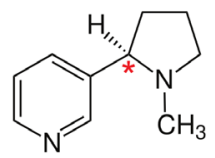

$R$-nicotine $(50 \%)$
B<smiles>c1cncc(C2=NCCC2)c1</smiles>

Myosmine

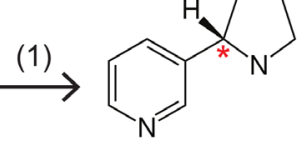

S-nornicotine
(2)

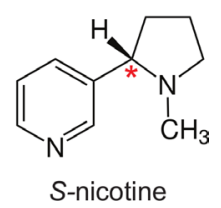

Figure 2 Structure and chemistry of synthetic nicotine. (A) Structures of $S$-nicotine and $R$-nicotine. The chiral centre of nicotine is labelled with a red asterisk. In tobacco leaf, $>99 \%$ of nicotine is present as $S$-nicotine. Synthetic 'Tobacco-Free Nicotine' (TFN), marketed by Next Generation Labs, is racemic, containing 50\% S-nicotine and 50\% $R$-nicotine. Pure synthetic $S$-nicotine is chemically indistinguishable from $S$-nicotine purified from tobacco. (B) Stereoselective synthesis of $S$-nicotine as described in a patent assigned to Zanoprima involving a biotechnological step. The starting material is myosmine, first stereoselectively converted to $S$-nornicotine using a recombinant enzyme (1), a NADH/NADPH-dependent imine reductase. S-nornicotine is then converted to $S$-nicotine through methylation (2).

use pure synthetic $S$-nicotine in their products, sourced from Contraf-Nicotex-Tobacco (CNT, Germany) (table 1). ${ }^{22}{ }^{23}$ CNT is known as the world's largest supplier of pharmaceutical grade nicotine extracted from tobacco for pharmaceutical products, including smoking cessation products such as nicotine gum, and the vaping industry. A trade publication cites a CNT executive stating that the company is selling highly pure pharmaceutical grade (USP) synthetic $S$-nicotine, voicing concerns about sales of racemic nicotine mixtures in consumer products. ${ }^{24}$ Patents assigned to CNT describe a manufacturing process first synthesising racemic nicotine from ethyl nicotinate and n-vinylpyrrolidone nicotinic acid, followed by a stereoselective purification using L-0,0'-dibenzoyl tartaric acid. ${ }^{25} 26$

Another E-liquid ingredient supplies vendor, eLiquiTech (Eldersburg, Maryland, USA), lists the company, Zanoprima Lifesciences (London, UK), as a supplier of synthetic $S$-nicotine (table 1). ${ }^{27}$ Zanoprima patented a process involving a biotechnological step for stereoselective synthesis of $S$-nicotine. ${ }^{28}$ The start material is myosmine, first stereoselectively converted to $S$-nornicotine using a commercially available recombinant enzyme, a NADH/NADPH-dependent imine reductase. $S$-nornicotine is then converted to $S$-nicotine through methylation (figure $2 \mathrm{~B}$ ).

Another patent for the production of racemic nicotine and subsequent enrichment of $S$-nicotine was awarded to NJOY, a major E-cigarette manufacturer, with similarities to CNT's process described above (table 1$).{ }^{29}$ Synthetic nicotine-containing

\begin{tabular}{llll}
\hline Table 1 & Manufacturers of synthetic nicotine & \\
\hline Manufacturer name & Starting material & Resulting product & Stereoselective step \\
\hline Next Generation Labs & Ethyl nicotinate & $\begin{array}{l}\text { Racemic }(50 / 50) \\
R / S-n i c o t i n e\end{array}$ & none \\
Contraf-Nicotex-Tobacco & Ethyl nicotinate & S-nicotine & $\begin{array}{l}\text { Stereoselective } \\
\text { recrystallisation }\end{array}$ \\
Zanoprima Lifesciences & Myosmine & S-nicotine & $\begin{array}{l}\text { Enzymatic } \\
\text { stereoselective step }\end{array}$ \\
& Rocemic (50/50) & S-nicotine & $\begin{array}{l}\text { Stereoselective } \\
\text { recrystallisation }\end{array}$ \\
\hline
\end{tabular}

E-cigarette products were also sold in the UK, containing NicTech-branded synthetic nicotine, licensed to a company named Intrepid Brands, with no identifiable patent source. ${ }^{30} 31$

Taken together, it is evident that several more simple and economic pathways have been developed lately for the synthesis of nicotine. A representative of NGL stated in 2019 that the company's product, the racemic mix of $R$-nicotine and $S$-nicotine, 'is only three to four times the current cost of tobaccoderived nicotine'. ${ }^{24}$ The price of highly pure synthetic $S$-nicotine is likely significantly higher.

\section{METABOLISM, PHARMACOLOGICAL EFFECTS AND ANALYTICAL DETECTION OF SYNTHETIC NICOTINE}

In the case a consumer product contains racemic synthetic nicotine, $50 \%$ of the nicotine content is present as $R$-nicotine. Little is known about the pharmacological and metabolic effects of $R$-nicotine in humans. Metabolic studies comparing the fate of $R$-nicotine in several animal species revealed stereoselective differences in the formation of oxidative metabolites and stereospecific N-methylation of nicotine enantiomers. ${ }^{32-34}$ The degradation kinetics of the resulting $S$-cotinine and $R$-cotinine also differed. In contrast to $S$-nicotine, $R$-nicotine did not induce weight loss in rats and did not trigger epinephrine release. ${ }^{3536}$ $R$-nicotine is a significantly less potent $(\sim 10$-fold) agonist of nicotine receptors than $S$-nicotine, however, both stereoisomers interfere with the production of certain lipid mediators involved in regulation of inflammation. ${ }^{3637}$

Hellinghausen et al devised a methodology to determine the concentrations of both $R$-nicotine and $S$-nicotine in E-liquids, nicotine patches and tablets, using a chiral stationary phase for enantioselective separation by High Performance Liquid Chromatography (HPLC), circular dichroism detection and electrospray ionisation mass spectrometry. ${ }^{38}$ The authors reported that one product contained twice as much total nicotine (sum of $R$-nicotine and $S$-nicotine) as stated on the product label, effectively listing only the $S$-nicotine strength, while for other products the amount listed on the label was equivalent to the total nicotine amount, with effectively half present as $S$-nicotine. ${ }^{38}$ These confusing labelling practices may expose unknowing users to high levels of $R$-nicotine, or to lower $S$-nicotine levels they are used to, causing them to purchase products with higher total nicotine content. The authors also detected impurities that require further characterisation. ${ }^{38}$

With highly pure synthetic $S$-nicotine available now in some E-liquids, how can synthetic $S$-nicotine be differentiated from tobacco-derived $S$-nicotine? The compounds are chemically identical and cannot be differentiated by standard analytical techniques. Comparison of carbon isotope content may offer a solution. Carbon exists as three isotopes ${ }^{12} \mathrm{C},{ }^{13} \mathrm{C}$ and ${ }^{14} \mathrm{C}$, with ${ }^{14} \mathrm{C}$ decaying with a half-life of 5700 years, a property used in radiocarbon dating of biological materials. ${ }^{14} \mathrm{C}$ is constantly replenished in the atmosphere and integrated into living plant matter, including tobacco plants and their alkaloids. In contrast, synthetic products, often produced from petrochemicals formed millions of years ago, have much lower ${ }^{14} \mathrm{C}$ content. For example, a ${ }^{14} \mathrm{C}$ analytical method has been developed to differentiate naturally sourced vanillin, a treasured flavourant, from vanillin produced from fossil sources. ${ }^{39}$ Depending on the metabolic pathways involved, natural products may also contain a higher ratio of ${ }^{13} \mathrm{C}$. High-temperature liquid chromatography coupled to isotope ratio mass spectrometry (HT-RPLC/IRMS) has become a standard approach to identify foods adulterated with synthetic additives, capable of differentiating between natural and synthetic caffeine, ethanol and sugars, among other chemicals. ${ }^{39} 40$ 
An HT-RPLC/IRMS method for determination of isotope ratios in $S$-nicotine has not been published yet, but should be feasible.

\section{SYNTHETIC NICOTINE: A CHALLENGE TO FDA'S AUTHORITY}

Puffbar's new product line represents a direct challenge to FDA's regulatory authority, potentially shortcutting the premarket tobacco product application (PMTA) requirement for E-cigarette products. While products containing synthetic nicotine were sold before, Puffbar's brand recognition and popularity among youth E-cigarette users should be a cause for concern. The entry of a market-leading nicotine supplier such as CNT into the synthetic nicotine market is further testing FDA. CNT supplies nicotine to the pharmaceutical industry for cessation products while at the same time supplying both tobacco-derived and synthetic nicotine to vape and smokeless product manufacturers. By selling products containing the more expensive synthetic nicotine, manufacturers demonstrate their willingness to forgo a part of their profits in exchange for staying in the market unimpeded, while manufacturers of products containing tobacco-derived nicotine have to manoeuvre the costly and complex PMTA process. By establishing opaque manufacturing and import networks and multisourced sales channels to web sellers, convenience stores and gas stations, brands such as Puffbar demonstrate their intent to maintain sales even while facing FDA enforcement action. ${ }^{41}$ At this time, it is not even clear whether Puffbar products contain synthetic nicotine. The analytical approaches described above should be employed for verification.

The Food, Drug and Cosmetics Act, amended by the 2009 Family Smoking Prevention and Tobacco Control Act (FSPTCA), defines a tobacco product as 'any product made or derived from tobacco that is intended for human consumption, including any component, part, or accessory of a tobacco product (except for raw materials other than tobacco used in manufacturing a component, part, or accessory of a tobacco product)'. The FDA seems confident that this definition authorises the agency to regulate at least some recreational synthetic tobacco products, stating that 'it's possible that a disposable, closed system device that contains an e-liquid with truly zero nicotine (or synthetic nicotine) would not be regulated by the FDA as a tobacco product, if it is not intended or reasonably be expected to be used in such a fashion. FDA intends to make these determinations on a case-by-case basis, ... ${ }^{42}$ Manufacturers clearly dispute these claims. For example, the Chief Executive Officer (CEO) of NGL is quoted with 'All indications from the FDA confirm our long-held position: TFN Nicotine products cannot be regulated under the Deeming Rule as they are not tobacco products, and we continue to believe that an open or closed system device for use with a choice of synthetic nicotine products will qualify as a nontobacco product. ${ }^{43}$

With multiple synthetic nicotine-containing product lines rapidly emerging, a case-by-case review strategy will likely be ineffective. If not regulated as a tobacco product, FDA could regulate synthetic nicotine as a drug, as proposed in a legal analysis by Zettler $e t ~ a l .{ }^{4}$ FDA attempted to regulate combustible and smokeless tobacco products as drugs in the 1990s, but lost this ability following the Supreme Court Ruling in FDA vs Brown \& Williams in which the court raised concerns that tobacco products marketed in the USA at the time could never meet the safety standards required for drugs and had no therapeutic benefits as required for drugs. ${ }^{44}$ However, FDA has always regulated nicotine replacement therapy products as drugs, including nicotine gum, lozenges and patches, a status that did not change with the enactment of the FSPTCA in 2009. Especially for products with added synthetic racemic nicotine, containing $50 \% R$-nicotine with unknown safety if consumed regularly, a case can be made for the stringent safety and efficacy review afforded to new drugs.

The analysis by Zettler et al also suggests that the intended use described by manufacturers and vendors of synthetic nicotine products often sets them apart. Manufacturers claim exceptional purity and health benefits compared with products containing tobacco-derived nicotine. Indeed, Puffbar advertises their product as containing 'A virtually tasteless, odorless nicotine without the residual impurities of tobacco-derived nicotine', while NGL states that 'TFN is devoid of many of the residual impurities that tobacco derived nicotine contain ... TFN is virtually tasteless and odorless ... there is no need to mask the offflavor and aroma of tobacco-based nicotine. ${ }^{715}$ NGL also claimed that 'specific ratios of the ' $\mathrm{R}$ ' to the ' $\mathrm{S}$ ' isomers could potentially offer nicotine use at satisfying but non-addictive or less addictive levels', while CNT claims that its synthetic $S$-nicotine is superior to the racemic version, stating 'If you look at the European and the U.S. Pharmacopeias, the percentage of $S$-isomers in nicotine must be higher than 99 percent. ${ }^{24} 45$ These statements, claiming superior drug-like properties, could provide a basis for FDA to categorise these products as drugs. This path will remain difficult though since classification as a drug requires a clear definition of its therapeutic benefit. Declaring synthetic nicotine products cessation aids would be a path forward, requiring manufacturers to remove their products from the market and conduct lengthy and costly FDA-qualifying clinical studies. For an industry selling E-cigarettes and other 'tobacco-free' products as recreational lifestyle products, this would be an unlikely route.

To remove any doubt over FDA's regulatory authority over synthetic nicotine products, federal legislators may need to expand the definition of tobacco products to include nicotine of any source, both natural and synthetic. Some US state regulations already include broader definitions of the term 'tobacco product'. For example, California and Massachusetts define tobacco product as 'A product containing, made, or derived from tobacco or nicotine that is intended for human consumption ...', leaving open the source of nicotine. ${ }^{46} \mathrm{FDA}$ and legislators need to act quickly since more and more synthetic nicotine products reach the USA and international markets, threatening to invalidate the regulatory gains made by the currently ongoing PMTA review process.

What this paper adds

- In February 2021, the disposable electronic cigarette brand, Puffbar, started selling a new product line in the United States, advertised as containing synthetic nicotine.

- Manufacturers claim that Food and Drug Administration (FDA) cannot regulate synthetic nicotine as a tobacco product, allowing them to skirt the costly premarket authorisation process. FDA may regulate synthetic nicotine as a drug instead.

- Recent advances in nicotine synthesis enabled manufacturing at a sufficiently competitive prices, however, presence of the inactive $R$-nicotine variant in some marketed versions raises safety and mislabelling concerns. Chemical analytical approaches to differentiate tobacco-derived from synthetic nicotine need to be optimised.

Twitter Sven-Eric Jordt @sejordt

Contributors SEJ carried out research, analysed the findings and wrote the manuscript.

Funding This work was supported by cooperative agreement U54DA036151 (Yale Center for the Study of Tobacco Product Use and Addiction: Flavours, Nicotine and 
Other Constituents) from the National Institute on Drug Abuse (NIDA) and FDA Centre for Tobacco Products (CTP), and grant R01ES029435 from the National Institute of Environmental Health Sciences (NIEHS) of the National Institutes of Health $(\mathrm{NIH})$.

Disclaimer The sponsors had no role in the design and conduct of the study; collection, management, analysis, and interpretation of the data; preparation, review, or approval of the manuscript; and decision to submit the manuscript for publication.

Competing interests Unrelated to the current research, SEJ reports receiving personal fees and non-financial support from Hydra Biosciences, Sanofi and the Research Institute for Fragrance Materials and non-financial support from GlaxoSmithKline Pharmaceuticals.

Patient consent for publication Not required.

Provenance and peer review Not commissioned; externally peer reviewed.

Open access This is an open access article distributed in accordance with the Creative Commons Attribution Non Commercial (CC BY-NC 4.0) license, which permits others to distribute, remix, adapt, build upon this work non-commercially, and license their derivative works on different terms, provided the original work is properly cited, appropriate credit is given, any changes made indicated, and the use is non-commercial. See: http://creativecommons.org/licenses/by-nc/4.0/.

\section{ORCID iD}

Sven-Eric Jordt http://orcid.org/0000-0001-6171-5622

\section{REFERENCES}

1 USFDA. CTP Glossary - Tobacco Product: USFDA, 2017. Available: https://www.fda. gov/tobacco-products/compliance-enforcement-training/ctp-glossary

2 Velo - Frequently Asked Questions, 2021. Available: https://www.velo.com/footerlinks/faq.html

3 Robichaud MO, Seidenberg AB, Byron MJ. Tobacco companies introduce 'tobacco-free' nicotine pouches. Tob Control 2020;29:e145-6.

4 Zettler PJ, Hemmerich N, Berman ML. Closing the regulatory gap for synthetic nicotine products. Boston Coll Law Rev 2018;59:1933-82.

5 Dai H, Hao J. Online popularity of JUUL and puff bars in the USA: 2019-2020. Tob Control 2020. doi:10.1136/tobaccocontrol-2020-055727. [Epub ahead of print: 13 Oct 2020].

6 USFDA. FDA Notifies companies, including puff bar, to remove flavored disposable e-cigarettes and Youth-Appealing E-Liquids from market for not having required authorization: USFDA, 2020. Available: https://www.fda.gov/news-events/ press-announcements/fda-notifies-companies-including-puff-bar-remove-flavoreddisposable-e-cigarettes-and-youth

7 Puffbar. Puffbar about - Tobacco Free: Cool Clouds Distribution Inc, 2021. Available: https://puffbar.com/pages/about-puff-bar

8 Zhang H, Pang Y, Luo Y, et al. Enantiomeric composition of nicotine in tobacco leaf, cigarette, smokeless tobacco, and e-liquid by normal phase high-performance liquid chromatography. Chirality 2018;30:923-31.

9 Tobacco BA. Manufacture of nicotine. 1964. Bates range: 100048807-8. Available: https://www.industrydocuments.ucsfedu/docs/lgcy0212

10 Reynolds R. Feasibility of synthetic nicotine production. 1967. Bates range: 500613486-9. Available: https://www.industrydocuments.ucsf.edu/docs/srhn0096

11 Myers L. Synthesis of nicotine. 1978. Bates range: Ig0292754-Ig5. Available: https:// www.industrydocuments.ucsf.edu/docs/gpyw0014

12 Wagner FF, Comins DL. Recent advances in the synthesis of nicotine and its derivatives. Tetrahedron 2007:63:8065-82.

13 Emura M, Matsuda H. A green and sustainable approach: celebrating the 30th anniversary of the asymmetric L-menthol process. Chem Biodivers 2014;11:1688-99.

14 RXVape. Tfn Florida key lime nicotine salts E-liquid Vape juice, 2021. Available: https:// rxvape.com/product/tfn-florida-key-lime-nicotine-salts-e-liquid-vape-juice/

15 NextGenerationLabs. NextGenerationLabs - What is TFN $\Theta$, 2021. Available: http:// www.nextgenerationlabs.com/

16 Arnold M. inventor; next generation Labs LLC, Kaival Labs LLC, assignee. Nicotine replacement therapy products comprising synthetic nicotine USA patent 10,610,526, 2020. Available: https://patents.google.com/patent/US20170189388A1

17 Next Generation Labs LLC has been granted a Notice of Allowance from China for its Process for The Preparation of (R-S) Synthetic Nicotine - Patent \#201580069647.2: Cision PRWeb, 2021. Available: https://www.prweb.com/releases/next_generation_ labs_Ilc_has_been_granted_a_notice_of_allowance_from_china_for_its_process_ for_the_preparation_of_r_s_synthetic_nicotine_patent_201580069647_21 prweb17809747.htm

18 20NE nicotine pouches 2021. Available: https://www.20nelabs.com/home

19 NIIN nicotine pouches 2021. Available: https://niinpouches.com/

20 20ne premium lab produced tobacco-free nicotine All-White pouches, Eucalyptus rush, 6mg (21 pouches) 1 can: Amazon, 2021. Available: https://www.amazon.com/ dp/B08TY8J2DH
21 FRĒ pouches FAQs 2021. Available: https://frepouch.com/pages/faq

22 E-liquid TT. Synthetic nicotine 2021. Available: https://teatimeliquid.com/pages/ synthetic-nicotine

23 Pawns F. S-isomer, the purest form of tobacco free nicotine, 2021. Available: https:// fivepawns.com/blogs/five-pawns-news-events/s-isomer-tobacco-free-nicotine

24 Rossel S. Synthetic nicotine is gaining acceptance tobacco reporter, 2019. Available: https://tobaccoreporter.com/2019/12/01/mirror-image/

25 Weber B, Pan B, Siegfried AG. Enantiomeric separation of racemic nicotine by addition of an 0,0'-disubstituted tartaric acid enantiomer patent US20200331883A1, 2019. Available: https://patents.google.com/patent/W02019121649A1/en

26 Weber BT, Lothschütz C, Pan B. Siegfried AG Contraf-Nicotex-Tobacco GmbH assignee. Preparation of racemic nicotine by reaction of ethyl nicotinate with $\mathrm{N}$-vinylpyrrolidone in the presence of an alcoholate base and subsequent process steps USA, 2020. Available: https://patents.google.com/patent/US20200331884A1

27 eLiquitech. The Future of Nicotine is Here - Introducting SyNic, 2021. Available: https://halibut-pomegranate-889p.squarespace.com/\#synic

28 McCague R, Narasimhan AS. Zanoprima Lifesciences Limited (London, GB), assignee. Process of making (S)-nicotine. USA patent 10,913,962, 2021. Available: https:// patents.google.com/patent/US10913962B2

29 Willis B, Ahmed MM, Freund W. Synthesis and resolution of nicotine. USA2020 09/01/2020. Available: https://patft.uspto.gov/netacgi/nph-Parser?Sect1=PT02\& Sect2=HITOFF \&u=\%2Fnetahtml\%2FPTO\%2Fsearch-adv.htm\&r=1\&f=G\&l=50\&d= PTXT\& $=1 \& S 1=10759776 \& 0 S=10759776 \& R S=10759776$

30 Riptide G2 bundle (2 pods + battery): Directvapor.com, 2021. Available: https://www. directvapor.com/riptide-g2-bundle/

31 Nictech 2.0 - Trademark by Intrepid Brands, LLC, Louisville, KY. Available: https:// trademark.trademarkia.com/n-20-nictech-88212589.html

32 Nwosu CG, Crooks PA. Species variation and stereoselectivity in the metabolism of nicotine enantiomers. Xenobiotica 1988;18:1361-72.

33 Nwosu CG, Godin CS, Houdi AA, et al. Enantioselective metabolism during continuous administration of S-(-)- and R-(+)-nicotine isomers to guinea-pigs. J Pharm Pharmacol 1988:40:862-9.

34 Jacob P, Benowitz NL, Copeland JR, et al. Disposition kinetics of nicotine and cotinine enantiomers in rabbits and beagle dogs. J Pharm Sci 1988;77:396-400.

35 Zhang $X$, Gong ZH, Nordberg A. Effects of chronic treatment with (+)- and (-)-nicotine on nicotinic acetylcholine receptors and $\mathrm{N}$-methyl-D-aspartate receptors in rat brain. Brain Res 1994;644:32-9.

36 Ikushima S, Muramatsu I, Sakakibara Y, et al. The effects of d-nicotine and l-isomer on nicotinic receptors. J Pharmacol Exp Ther 1982;222:463-70.

37 Saareks V, Mucha I, Sievi E, et al. Nicotine stereoisomers and cotinine stimulate prostaglandin E2 but inhibit thromboxane B2 and leukotriene E4 synthesis in whole blood. Eur J Pharmacol 1998:353:87-92.

38 Hellinghausen G, Lee JT, Weatherly CA, et al. Evaluation of nicotine in tobacco-freenicotine commercial products. Drug Test Anal 2017;9:944-8.

39 Mao H, Wang H, Hu X, et al. One-Pot efficient catalytic oxidation for Bio-Vanillin preparation and carbon isotope analysis. ACS Omega 2020;5:8794-803.

40 Zhang L, Kujawinski DM, Federherr E, et al. Caffeine in your drink: natural or synthetic? Anal Chem 2012;84:2805-10.

41 Alexander S, LaVito A, Upstart LA. Upstart L.A. company pulls back puff bar single-use vaping product after outcry, 2020. Available: https://www.latimes.com/business/story/ 2020-02-20/vaping-loophole

42 USFDA. Commonly Asked Questions: About the Center for Tobacco Products: The product I manufacture contains no substance made or derived from tobacco, e.g. is zero-nicotine, or has synthetic nicotine or nicotine made from tomatoes. Is my product subject to FDA regulation? : USFDA, 2020. Available: https://www.fda.gov/tobaccoproducts/about-center-tobacco-products-ctp/commonly-asked-questions-aboutcenter-tobacco-products\#14

43 NextGenerationLabs. FDA Finally Addresses Synthetic Nicotine; Confirming Next Generation Labs' Position that Synthetic Nicotine Is Not A Tobacco Product: Intrado GlobalNewswire, 2017. Available: https://www.globenewswire.com/fr/news-release/ 2017/01/20/909720/0/en/FDA-Finally-Addresses-Synthetic-Nicotine-ConfirmingNext-Generation-Labs-Position-that-Synthetic-Nicotine-Is-Not-A-Tobacco-Product. html

44 FDA v. Brown \& Williamson Tobacco Corp. Sect. 529 U.S. 120, 172 (2000). Available: https://supreme.justia.com/cases/federal/us/529/120/

45 Specific nicotine isomers ratios could potentially offer nicotine use at Satisfying but Non-Addictive levels as revealed by next generation Labs CEO Vincent Schuman: CISION PRWeb, 2017. Available: https://www.prweb.com/releases/2017/11/ prweb14911138.htm

46 Business and Professions Code - BPC DIVISION 8.5. STOP TOBACCO ACCESS TO KIDS ENFORCEMENT ACT [22950 - 22964] (Division 8.5 added by Stats. 1994, Ch. 1009, Sec. 1.) $22950.5,2016$. Available: https://leginfo.legislature.ca.gov/faces/codes_ displaySection. $x$ html?lawCode=BPC\&sectionNum $=22950.5$ 